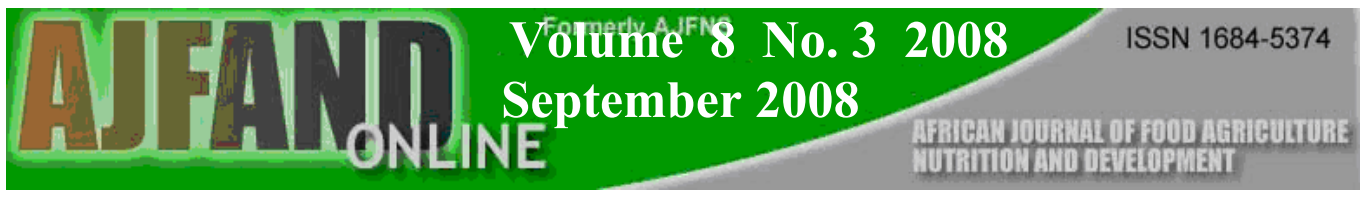

\title{
FACTORS LIKELY TO ENHANCE MYCOTOXIN INTRODUCTION INTO THE HUMAN DIET THROUGH MAIZE IN KENYA
}

\author{
Wilkister K. Nyaora Moturi
}

Egerton University, Department of Environmental Science

P.O. BOX 536, Egerton, Kenya

E-mail: moturi33@yahoo.com

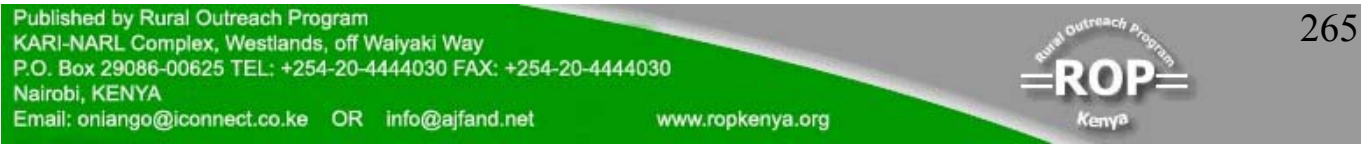




\begin{abstract}
Moulds probably contaminate and spoil more foods than any other groups of microorganisms. They render contaminated food not only unpalatable, but also unsafe for consumption by producing toxins. In Kenya, several incidences of acute food poisoning due to mycotoxins have occurred, and especially through the staple food, maize. Chronic exposure to mycotoxins has been linked to liver cancer, hepatitis infections, impaired immunity and stunted growth in children. Several factors may enhance the occurrence of mycotoxin in the human diet in Kenya. These include eating habits, existing marketing problems which encourage long storage periods; the pre and post harvest practices that encourage build up of moisture and thus encourage mould growth; lack of preparedness in handling the large quantities of maize produced due to the success of hybrid maize technology, ignorance and poverty. This is aggravated by the fact that there are no strict regulations that impose limits on the concentration of mycotoxins in maize that is marketed in the country as well as lack of relevant technology required in monitoring fungi and mycotoxins in the grains. Mechanisms put in place to deal with such situations can be successful, only if the several factors that contribute towards this situation are well understood. The paper discusses these factors and gives some recommendations for action and further research. The recommendations include coming up with agronomic practices that discourage mould growth; improved pre and post harvest practices; nutritional education and induction of behavioural change as regards food habits; efficient and functioning systems of marketing and pricing of domestically consumed maize, especially within the East African Community; research to identify factors leading to S-strain dominance in semi-arid regions of Kenya; identification of non toxic strains that are highly effective against the S-strain; research on how malnutrition aggravates aflatoxicosis and use of additives and other methods for rendering poor quality grain safe for consumption.
\end{abstract}

Key words: diet, factors, hepatitis, maize, mycotoxins. 


\section{INTRODUCTION}

Maize is the most widely grown cereal in Kenya. It accounts for more than $75 \%$ of the total cereal area and more than $60 \%$ of the total cereals marketed. It is the staple food in the country and is mainly grown by smallholder farmers who together with their families account for $70 \%$ of the Kenyan population. Maize accounts for over half of the smallholder's land devoted to food crops and nearly all small holders grow some variety of maize to eat and market [1].

Mould growth on maize is very common, especially in warm humid climates, because it is a good substrate for mould growth, and especially those that produce aflatoxin, due to its low nitrogen content. The high carbohydrate content provides the two carbon precursors for mycotoxin synthesis [2]. Currently, over 200 mycotoxins are known [3], but only those occurring naturally in foods are of significance in terms of food safety. These are produced mainly by species of Aspergillus, Penicillium and Fusarium [4,5]. These species have been found during growth, harvest and storage. They occur worldwide in air and soil and cause contamination in cereals, legumes, cotton seeds and tree nuts before harvest and after harvest, during handling in storage and in processing [6].

Well documented human mycotoxicoses include ergotism [7], alimentary toxic aleukia [8], Balkan endemic nephropathy and acute aflatoxicoses [9]. Several cases of acute aflatoxicoses have been reported in Kenya in the past. In March to June, 1981, several people were hospitalized in the Eastern province of Kenya. More than $50 \%$ of those admitted died. In 1982, there was another episode, with a $60 \%$ mortality [10]. There were similar outbreaks of acute aflatoxicosis in the same province in 2001, 2004, 2005 and 2006 where many people and especially children died $[11,12,13]$. The 2004 outbreak of acute aflatoxicosis in Kenya was one of the most severe episodes in history of human aflatoxin poisoning recorded. A total of 317 cases were reported by 20 July 2004, with a case fatality rate of $39 \%[14,15]$.

Epidemiological studies indicate that chronic consumption of foods contaminated with aflatoxins may play a major role in the high incidences of liver cancer prevalent in south East Asia, China and several parts of sub-Saharan Africa [8, 16, 17]. A study conducted in various parts of Kenya [10] established a positive relationship between exposure to aflatoxin and prevalence of hepatitis infections. The highest level of aflatoxin exposure was in Western Highlands of Kenya and Central province. The staple diets of communities living in these regions have maize as a dominant component. The study gave additional support to the hypothesis that aflatoxin is a human liver carcinogen [18]. In addition to secondary deficiency of nutrients, high exposure to aflatoxins has been implicated as another cause of impaired growth leading to stunting of children across sub-Saharan Africa [19]. In farm and laboratory animals, chronic exposure to aflatoxins has been proven to compromise immunity and interfere with protein metabolism and multiple micronutrients that are critical to health. These effects have not been widely studied in humans, but the available information indicates that at least some of the effects observed in animals also occur in

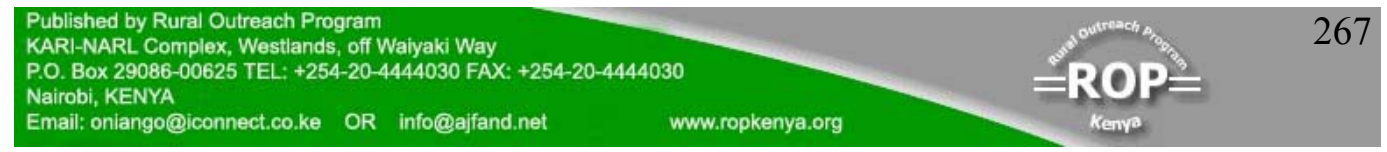


humans [20]. In humans therefore, the aflatoxin exposure and the toxic effects of aflatoxins on immunity and nutrition may combine to negatively affect health factors (including HIV infection) that account for more than $40 \%$ of the burden of disease in developing countries where a short lifespan is prevalent [17].

\section{FACTORS DETERMINING MAIZE CONTAMINATION IN KENYA}

\section{Feeding habits}

Most Kenyans are exposed to low and medium level doses of a wide spectrum of fungal poisoning through regular consumption of maize products. On average, Kenyans eat maize products at the rate of $0.4 \mathrm{~kg} / \mathrm{person} /$ day; hence even the lowest amount of exposure is cumulatively likely to be of severe health risk [21]. The low levels of exposure are asymptomatic and it is only when crisis levels that kill are reached that action is taken. In addition to eating "ugali" (paste made from maize flour) of sub-standard maize flour available in the market, many people are exposed through drinking of "busaa", a local brew which is prepared from fermented maize and millet flour. Besides, maize is a major component in livestock and poultry feeds.

Samples obtained from ordinary grocery stores, kiosks, supermarkets and open air markets in Nairobi, Kenya were found to be contaminated with moulds that produce aflatoxins, fumonisms and ochratoxins among other mycotoxins. About $70 \%$ were contaminated with aflatoxins, and $5 \%$ with similar fungal poisonous substances [21]. In 2004, about 2000 bags of maize meant for the school feeding programme in Mbeere district of Eastern province of Kenya was impounded when it was found to be contaminated by high levels of aflatoxin. The maize was part of a 3,389-bag consignment donated by the World Food Programme for the school feeding programme [16].

\section{Marketing}

The marketing and pricing of maize in Kenya was tightly controlled by the government through the National Cereal and Produce Board (NCPB) until 1986 when liberalization took place. With the liberalization of the maize marketing, the NCPB's basic roles would be to manage strategic national maize reserves and be the buyer and seller of last resort [22].

Studies undertaken by Nyangito and Ndirangu [23] indicate that only $36 \%$ of this maize is sold through NCPB. NCPB mainly deals with the large scale farmers. Consequently, many farmers dispose the product at lower prices in private markets whose conditions for accepting maize are less stringent. Liberalization, therefore, has led to differentiation in maize quality whereby NCPB buys high quality maize while the private market absorbs most of the "low quality" maize. This has a higher percentage of damaged grains, and the moisture content is high. Damaged grain provides an opportunity for a fungus to circumvent the natural protection of the integuments and establish infection sites in the vulnerable interior [4]. Studies done in Burundi by Munimbazi and Bullerman [24] showed that mould growth in maize is favoured by high moisture content. In their study, the maize affected exhibited high 
levels of Fusarium moniliforme, F. semitectum, F. proliferatum and F. subglutinas. There were high levels of the genus Aspergillus which gives rise to aflatoxins.

\section{Long storage periods}

During conditions of bumper harvests, farmers are faced with a situation where they can not profitably dispose of their maize. In addition, maize entering the market from the neighboring countries of Uganda and Tanzania retails at lower prices due to lower production costs. This means that in most cases, farmers are ready to harvest their next crop before they can dispose of their old one. Whenever such situations occur, maize has to be stored for long periods of time, before being disposed of, or before being utilized.

Experiments carried out by Eriksson [25] with the different types of storage structures used in Kenya, established that the main constraint in most traditional storage structures is that they do not allow for optimal free ventilation and thus a long preharvest drying is required before maize can be stored safely . Moulds were present in maize stored in all types and sizes of structures and it was difficult to establish if mould infection had occurred during storage or in the field. A project based on onfarm grain storage in Maseno, Western Kenya established that maize storage at different temperatures and moisture content is the primary factor affecting mould and fungi growth [26]. In the same project, it was also observed that prolonged storage, regardless of the storage structure encouraged mould growth. Insect and mould infestation might not be noticeable at harvest, but the build-up of the infection will accelerate later during long storage periods. In addition, the transport chain from village to markets through various middlemen, sometimes under adverse weather conditions may not always be satisfactory, thus there is considerable opportunity for mould and mycotoxin contamination [27].

\section{Lack of preparedness in handling success in hybrid maize technology}

The development of hybrid maize technology resulted in increased maize yields. However, the success of hybrid maize did confront the government with policy questions concerning marketing and storage. At certain seasons, there are such bumper harvests, that the NCPB lacks the capacity to store all the maize. Farmers, most of who do not have adequate storage facilities for storing the maize, are turned away with their maize. If there was adequate storage capacity, even the strategic maize reserves could be enhanced. Little support has been given to establishing secondary industries based on maize [1].

\section{Pre and Post harvest practices}

Traditionally, most farmers leave their maize after it has matured at a moisture content of approximately $30 \%$ in the field for natural drying until the moisture content is reduced to $18 \%$ by the time the maize is harvested [28]. During this long preharvest drying period in the field, the maize is exposed to negative effects of wind and rain, and the attacks of insects, birds and moulds. Eriksson [25] established that the most critical interval of drying maize in Kenya is from when it starts drying up, down to approximately $20 \%$ moisture content. During this interval, moulds occur more

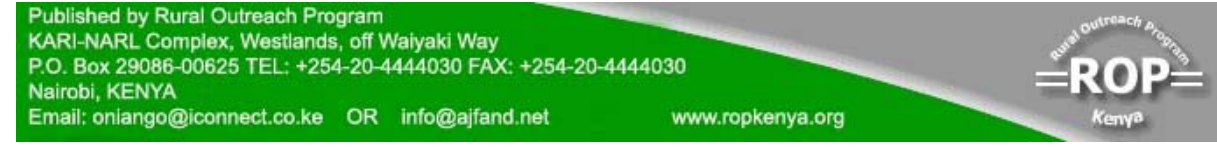


easily. Cutting and piling up of maize against a tree or fence in the fields is one of the methods used for post harvest drying of the crop in Kenya. The maize is exposed to all elements weather, including rain, which is increasingly becoming more erratic. This leads to prolonged drying periods, thus increasing the chances of infestation. The other method involves storing the maize cobs in traditional baskets and round cribs. The calculated time of drying maize on cobs from $25 \%$ to $19 \%$ moisture content in the traditional baskets and round cribs in Western Kenya was found to be 65 days and 58 days respectively. Although the safe allowable time for Kenya cob maize to be dried under prevailing environmental conditions is not known, the conclusion was that the period was too long and should raise concern [26].

\section{Lack of regulations and control measures}

Mycotoxin control measures have been implemented for agricultural commodities entering international trade or located in countries with centralized or large scale buying and distribution systems. However, in developing countries, where $70 \%$ of the food consumed is that which is grown locally, regulatory measures are difficult to implement. Because of the stringent mycotoxin control measures being maintained by countries importing food grains and because of the need of exporting countries to earn foreign exchange, the best of the commodities are often sold abroad while the substandard or contaminated commodities are retained for domestic use [27]. In Kenya, mycotoxin regulation is governed by Foods, Drugs and Chemical Substances Regulations (Kenya Gazette, 01.07.1978) and it is under the Ministry of Health. Official methods of Analysis are used [29]. These regulations are not enforced as required since enforcement is seen to occur sporadically during acute cases of poisoning. Enforcement of regulations requires reliable analytical methods of control, which may not be readily available in developing countries [30]. Samples have to be transported to urban areas for analysis, yet most maize production and marketing occurs in the rural areas of Kenya. In the 2004 outbreak, samples had to be transported to the National Public Health Laboratory Services in the capital city, Nairobi [31]. Characterization of causal agents is an important initial step for development of mycotoxin management procedures, yet such technology is not widely available in Kenya. Sub-samples in the 2004 outbreak had to be taken to the United States from the National Public Health Laboratory Services for fungal analyses [32].

\section{Poverty and ignorance}

The poor are dominant among subsistence farmers, pastoralists in the drier parts of Kenya, casual and unskilled labourers, households headed by females and unskilled persons, the handicapped, orphans and street children. It is also evident from existing analyses that poverty is prevalent in rural Kenya [33]. In most cases, the poor are keen to put food on the table with little regard for its quality. Foods of poor quality retail for lower prices and this is what most of the poor can afford. In some cases, they are willing to consume food that has already been condemned as unfit for human consumption, if only to survive. 
Many people are not knowledgeable on the potential dangers posed by some of the contaminants that are found in food, right from the food producers to the consumers. The producers are not aware of the repercussions of their pre and post harvest practices, nor are the consumers aware of their rights as consumers to have food that is wholesome and free from contaminants. Food contaminated by mycotoxins may not show visible signs of infection, even to an experienced farmer. Due to adherence to cultural beliefs in many communities, symptoms of acute food poisoning may be taken for witchcraft and other form of illnesses, as was witnessed in the acute aflatoxicosis incidences in May, 2004 in Eastern Kenya. In most instances, people visit the hospital as a last resort after they have tried various alternatives, mostly traditional. The death casualty was higher in children who had been given herbal treatment prior to being hospitalized [34]. People failed to recognize the symptoms as food poisoning, thus consumption of the poisonous maize continued even long after an alert had been sounded, regarding the suspect maize in the market.

\section{The way forward: recommendations}

From the hazard point of view, it might be desirable to limit the toxin of concern to the lowest possible level. However, zero tolerance may be impractical because mycotoxins are natural toxicants that often cannot be completely excluded from the food chain $[30,35]$. It is necessary to adopt a multidisciplinary approach and consider the various factors in trying to deal with the problem. The following are some recommendations for action and further research:

1. Research findings have revealed that drought stress, a common feature in most of sub-Saharan Africa (and a feature that commonly occurs in most maize growing areas in Kenya) favours Aspergillus flavus growth, in which it has a competitive advantage over other grain infesting fungi $[23,36]$. There is need to come up with favourable agronomic practices under the prevailing conditions that discourage mould growth.

2. Fungal analyses carried out after the 2004 aflatoxicosis in Kenya indicate that the outbreak was caused by the S-strain of A. flavus [32]. The S-strain, which was not previously found in Africa [16, 37], was repeatedly isolated from all 104 maize samples from affected districts. The S-strain is more toxic because it produces more aflatoxin that the other strains. There should be further research to identify factors leading to S-strain dominance in semiarid regions of Kenya. This may result in management procedures effective in both Kenya and other regions where the S-strain is an important etiologic agent of aflatoxin contamination.

3. Currently, non-toxic A. flavus L-strain isolates are used to competitively exclude aflatoxin producers during crop infection and thereby limit contamination in U.S. agriculture [38, 39]. These highly competitive atoxigenic strains of Aspergillus are applied to soil after which they spread to maize, excluding the toxic strains [40]. Scientists at the International Institute of Tropical Agriculture (IITA) have assembled a set of eight non-toxin 
producing strains of Aspergillus flavus in Nigeria, capable of radically reducing aflatoxin in maize by $99 \%$ [41]. Deployment of similar technologies in Kenya could provide a promising strategy for prevention of future aflatoxicoses in East Africa while enhancing export possibilities for maize [42]. This should be accompanied by training of experts in this field, who can then embark on further research to domesticate the technology.

4. The prognosis for aflatoxicosis for children with Kwashiorkor in various parts of West Africa was shown to be worse [19]. The incidences of acute aflatoxicosis in Kenya have always occurred in regions of food stress, where cases of malnutrition are likely to be higher. Incidentally, the mortality rates have been higher in children. Could malnutrition be aggravating acute aflatoxicosis? There is need for further research in this area.

5. Definitely, there is need for improved pre and post harvest practices in decreasing the likelihood of mould infection. There is need to use farmer participatory methods, so as to assess the costs to the farmer of adopting improved management practices. This will enhance adoptability and will be more sustainable.

6. Most maize growers in Kenya being smallholders, and falling below the poverty line, it would be difficult to convince them to discard contaminated maize. Contaminated grain can be sold to ethanol producing plants, since aflatoxins do not appear in distilled alcohol [43]. The spent grain however can not be used as animal feed, so to compensate for this, it can be purchased at a slightly lower price. Some of the developed-country approaches to the management of aflatoxins can be adopted. These include using food additives to make the grain safe for farm animals [17]. These include detoxifying the grain with anhydrous ammonia by well trained personnel. The ammonia reacts with aflatoxin molecule to destroy its toxicity. Proper treatment can reduce aflatoxin concentrations by $95 \%$ or more. Livestock however may be reluctant to eat if a strong ammonia smell is present [44]. This can bring about alternative markets for the poorest quality grains so as to help remove it from the human food sector.

7. There is need for change in feeding habits so that people do not rely heavily on maize as their only staple diet (such that they need to have it in their meals regardless of its quality). There is need for nutritional education and rigorous campaigns to enlighten the people about the health hazards of aflatoxin and alternatives to maize, such as sorghum, millet and other sources of carbohydrates in the diet. In combating malnutrition (which has been shown to enhance aflatoxicosis), families can be enabled to improve their diets even without additional income. This can be done through education and campaigns through already existing networks such as Agriculture and Home Economics extension agents already working in the field. According to World Bank [44], this is often the most cost effective way of improving nutritional 
status, since in many cases, lack of nutritional knowledge is a major cause of malnutrition.

8. There is a need to ensure compliance of regulations regarding mycotoxins. With liberalization of the maize market, and the re-emergence of the East Africa Community, there is need for collaboration between the three East African countries in enforcing standards for food/feed within countries and between borders. There should be more cooperation between the member countries in dealing with regulations. More resources need to be allocated in order to finance compliance, which should be proactive, rather than reactive, as has been the case. It should be noted that no method of analysis exists for detecting zero tolerances; therefore, tolerance levels should be based on a risk assessment approach rather than on analytical limitations, that is, levels below which no detection is possible by analytical means [31].

9. Efficient and functioning systems of marketing and pricing of domestically consumed maize should be developed and sustained. Industries that use maize as their raw material should be established, especially in areas that produce maize in great quantities, in order to avoid prolonged maize storage, and transportation under unfavourable conditions. The National Cereals and Produce Board offers drying services for grain, but it is too expensive for farmers, given the high production costs and low sale prices for the crop. There should be a move towards better pricing of the crop or reducing the costs of inputs, so that farmers can afford such services. This should be coupled with increased storage facilities at the NCPB stores. These will not only decrease incidences of aflatoxicosis and food spoilage, but will also enhance food security in Kenya. 


\section{REFERENCES}

1. USAID. Kitale maize: The limits of success. A.I.D. Project Impact Evaluation Report, No.2. Agency for International Development, Nairobi, Kenya, 1980.

2. Wiseman DW and RL Buchanan Determination of glucose level needed to induce aflatoxin production in Aspergillus parasiticus. Can. J. Microbiol. 1987; 33: 828-830.

3. Cole RJ and RH Cox Handbook of toxic fungal metabolites. Academic Press, New York, 1981.

4. Bullerman LB Significance of mycotoxins to food safety and human health. J. Food Protect. 1979; 42: 191-196.

5. Cotty PJ Aflatoxin-producing potential of communities of Aspergillus Flavi from cotton producing areas in the United States. Mycol. Res. 1997; 101:698704.

6. Cardwell KF and PJ Cotty Distribution of Aspergillus section Flavi among soils from the four agroecological zones of the Republic of Benin, West Africa. Plant Dis. 2002; 86:434-439.

7. Mattosian MK Poisons of the past: moulds, epidemics and history. Yale University Press, New Haven, CT, USA, 1989.

8. Dvorackova I Aflatoxins and human health. CRC Press, Inc., Boc Raton, Florida, 1990.

9. Krogh P Role of ochratoxin in disease causation. Food Chem. Toxicol. 1992; 30: 213-224.

10. Nagindu A, Johnson BK., Kenya PR., Ngigra JA., Ocheng DM., Nandwa H, Omondi TN., Jansen AJ., Ngare W, Kaviti JN., Gatei D, and TA Siongok. Outbreak of acute hepatitis caused by aflatoxin poisoning in Kenya. Lancet 1982; (1):1346-1348.

11. Daily Nation October 3, 2001

12. Azziz-Baumgartner CI, Lindblade K, Gieseker K, Rogers HS, Kieszak S, Njapau H, Schleicher R, McCoy LF, Misore A, DeCock K, Rubin Slutsker CL and the Aflatoxin Investigative Group. Case-control study of an acute aflatoxicosis outbreak, Kenya, 2004. Environ. Health Perspect. 2005; 113:1779-1783.

13. World Health Organization AFRO Food Safety Newsletter. Issue No 2. July 2006. www.afro.who.int/des [13/4/2008] 
14. Nyikal, J,. Misore A, Nzioka C, Njuguna C, Muchiri E, Njau J, Maingi S, Njoroge J, Mutiso J, Onteri J, Langat A, Kilei IK, Nyamongo J, Ogana G, Muture B, Tukei P, Onyango C, Ochieng W, Tetteh C, Likimani S, Nguku P, Galgalo T, Kibet S, Manya A, Dahiye A, Mwihia J, Mugoya I, Onsongo J, Ngindu A, DeCock KM, Lindblade K, Slutsker L, Amornkul P, Rosen D, Feiken D, Thomas T, Mensah P, Eseko N, Nejjar A, Onsongo M, Kesell F, Njapau H, Park DL, Lewis L, Luber G, Rogers H, Backer L, Rubin C, Gieseker KE, Azziz-Baumgartner E, Chege $W$ and A. Bowen. Outbreak of aflatoxin poisoning - Eastern and Central Provinces, Kenya, January-July 2004. Morb. Mortal. Wkly. Rep. 2004; 53:790-793.

15. Lewis L, Onsongo M, Njapau H, Rogers HS, Luber G, Kieszak S, Nyamongo J, Backer L, Dahiye AM, Misore A, DeCock K, Rubin C, and the Kenya Aflatoxicosis Investigation Group. Aflatoxin contamination of commercial maize products during an outbreak of acute aflatoxicosis in Eastern and Central Kenya. Environ. Health Perspect. 2005; 113:1763-1767.

16. Bennett JW and M Klich Mycotoxins. Clin. Microbiol. Rev. 2003; 16:497516.

17. Williams JH, Phillips TD, Jolly PE, Stiles JK, Jolly CM and D Aggarwal Human aflatoxicosis in developing countries: a review of toxicology, exposure, potential health consequences, and interventions. Am. J. Clin. Nutr. 2004; 80(5):1106-1122

18. Autrup H, Seremet $\mathbf{T}$, Wakhisi $\mathbf{J}$ and $\mathbf{A}$ Wasunna Aflatoxin exposure measured by urinary excretion of aflatoxin B1-Guanine adduct and hepatitis B virus infection in areas with different liver cancer incidence in Kenya. Am. Assoc. Cancer Res. 1987; 47(13): 3430-3433

19. Cardwell KF Mycotoxin contamination in foods-Anti-nutritional factors. In Proceedings on Improving Human Nutrition through Agriculture, Los Banos, Phillipines, 1999; 27-34.

20. www.engormix.com. Nairobi- Maize deaths tip of iceberg. www.engormix.com/e noticias list.asp?NRO=675 [17/9/2004]

21. Daily Nation September 2, 2004

22. Government of Kenya Development Plan for 1994-1996. Government Printing Press, Nairobi, Kenya, 1994.

23. Nyangito $H$ and $L$ Ndirangu Farmer's response to reforms in the marketing of maize in Kenya: A case study of Trans-Nzoia District. Discussion paper No. DP003/97. Institute of Policy Analysis and Research, Nairobi, Kenya, 1997. 
24. Munimbazi C and LB Bullerman Moulds and mycotoxins in foods from Burundi. J. Food Protect. 1996; 59(8): 869-875.

25. Eriksson L Natural drying of early harvested maize on cobs in raised rectangular cribs with slatted floor. In Proceedings on Maize conservation on the farm. Kisumu, Kenya, 1986; 80-86.

26. Fossen LV Cob maize drying trials. In Proceedings on Maize conservation on the farm. Kisumu, Kenya, 1986; 14-21.

27. Bhat RV Mould deterioration of agricultural commodities during transit: Problems faced by developing countries. Int. J. Food Microbiol. 1988; 7(3): 219-225.

28. Rombo F Aflatoxin analysis of maize grains. In Proceedings on Maize conservation in the farm, Kisumu, Kenya, 1986; 69-75.

29. Food and Agriculture Organization, FAO Worldwide Regulations for Mycotoxins in food and feed in 2003. Food and Agriculture Organization of United Nations, Rome, 2004.

30. Food and Agriculture Organization, FAO Worldwide regulations for mycotoxins 1995: A Compendium. Food and Agriculture Organization of United Nations, Rome, 1997.

31. Muture BN and G Ogana Aflatoxin levels in maize and maize products during the 2004 food poisoning outbreak in Eastern Province of Kenya. East Afr. Med. J. 2005; 82:275-279.

32. Probst C, Njapau $\mathbf{H}$ and PJ Cotty Outbreak of an Acute Aflatoxicosis in Kenya in 2004: Identification of the Causal Agent. Appl. Environ. Microbiol. 2007; 73(8):2762-2764.

33. Institute of Policy Analysis and Research (IPAR) Budgeting for Poverty Reduction in Kenya: IPAR's contribution on Kenya's Poverty Reduction Strategy Paper (PRSR) 2000-2003. Policy Quarterly, 2000; 4.

34. Daily Nation May 20, 2004

35. Food and Agriculture Organization Newsroom FAO seeks emergency assistance for Kenyan Agriculture. www.fao.org/newsroom/en/news/2004/49527/-

36. Udoh JM Aflatoxin content of maize grains affected by agricultural practices in five agro ecological zones of Nigeria. PhD dissertation. Nigeria: University of Ibadan, 1997. 
37. Cotty PJ and KF Cardwell Divergence of West African and North American communities of Aspergillus section Flavi. Appl. Environ. Microbiol. 1999; 65:2264-2266.

38. Cotty PJ Influence of field application of an atoxigenic strain of Aspergillus flavus on the population of $A$. flavus infecting cotton bolls and on the aflatoxin content of cottonseed. Phytopathol. 1994; 84:1270-1277.

39. Dorner JW Biological control of aflatoxin contamination of crops. J. Toxicol. Toxin Rev. 2004; 23:425-450.

40. Garber RK and PJ Cotty Formation of sclerotia and aflatoxins in developing cotton bolls infected by the S strain of Aspergillus flavus and potential for biocontrol with an atoxigenic strain. Phytopathol. 1997; 87:940-945.

41. International Institute of Tropical Agriculture, IITA Scientists found solution for aflatoxin contamination.

http://www.iita.org/cms/details/who_details.aspx?a=364\&z=336. [11/4/2008]

42. Bankole SA and A Adebanjo Mycotoxins in food in West Africa: current situation and possibilities of controlling it. Afr. J. Biotechnol. 2003. 2:254263.

43. Vincelli P, Parker G and S McNeill Aflatoxins in Corn. University of Kentucky, USA, 1995.

44. World Bank World Development Report: Investing in Health. Oxford University Press, New York, 1993. 